\title{
Stability of vapor phase water electrolysis cell with anion exchange membrane
}

\author{
Gino Heremans, Tom Bosserez, Johan A. Martens and Jan Rongé* \\ Centre for Surface Chemistry and Catalysis, KU Leuven, Celestijnenlaan 200F, B-3001 Heverlee, Belgium. \\ *Corresponding author, e-mail: jan.ronge@kuleuven.be
}

The authors declare no conflict of interest

Keywords: Solar fuels, Water electrolysis, Anion exchange membrane, earth abundant catalysts, vapor phase electrolysis

Highlights:

- Similar initial water splitting activity was found in vapor and liquid phase operation.

- In vapor-fed water electrolyzer a steady electric potential was achieved over a period of $90 \mathrm{~h}$.

- Water transport limitations were revealed to be a rate-determining factor.

- Water contained in the membrane acts as a reservoir for water splitting.

\begin{abstract}
:
The production of renewable hydrogen gas with a vapor-fed solar hydrogen generator is an appealing strategy. In such all solid-state standalone device no liquid electrolyte is required. The use of an anion exchange membrane separating cathode and anode compartments is particularly advantageous and its performance matches the performance of liquid phase electrolysis. In this work, a vapor-fed water electrolyzer was investigated comprising a poly(vinyl alcohol) anion exchange membrane impregnated with $4 \mathrm{M} \mathrm{KOH}$ solution and Ni-based catalysts. The performance was evaluated over time periods of hours to days. The vapor fed device showed similar initial activity as an electrolysis setup with the same electrodes immersed in $1 \mathrm{M} \mathrm{KOH}$ liquid electrolyte. To sustain a current density of $10 \mathrm{~mA} / \mathrm{cm}^{2}$, it was observed that the required potential initially increased but eventually reached a steady state at $c a .1 .9 \mathrm{~V}$. From a $\mathrm{D}_{2} \mathrm{O}$ isotope labelling experiment of the vapor phase, it was noticed that the system initially consumed $\mathrm{H}_{2} \mathrm{O}$ absorbed in the membrane to produce $\mathrm{H}_{2}$. After this water of the membrane was consumed, water to be split is taken from the vapor phase and water mass transfer limitation starts occurring. Once water mass transfer and splitting reactions are matched, a steady state potential is reached. The results of this work are encouraging and pave the way to efficient stable operation of vapor-fed solar hydrogen generators.
\end{abstract}

\section{Introduction}

Solar power is by far the biggest source of renewable energy available [1]. Capturing this solar energy and storing it in chemical bonds is acknowledged as a way to provide energy security [2]. Solar hydrogen generation fits well in this strategy [3], and it allows to store solar energy on a seasonal timespan [4,5]. The technology does not involve formation of any harmful byproducts. Several routes are available to produce hydrogen gas from sunlight, of which photovoltaic (PV) coupled electrolysis and photoelectrochemical cells have achieved the highest efficiencies [6].

For both device concepts, most of the research has dealt with operation in liquid phase. Another option that is recently being explored is the use of water vapor as water source [7-16]. In this concept, water could be directly taken from the air to feed the solar hydrogen generator. Since PV panels generate limited current densities (ca. 10 $\mathrm{mA} / \mathrm{cm}^{2}$ ), sufficient water is available in the air and it can be delivered by natural convection [2,8]. Such type of device would be completely solid-state and would require no peripherals for water supply [2], allowing it to be placed on any location such as on rooftops [8] or at sea [10]. Spurgeon and Lewis showed that in this low current density regime vapor phase operation is able to be more efficient compared to liquid phase because of favored thermodynamics and avoided bubble formation [9].

Recently, our research team demonstrated for the first time a vapor-fed electrolysis device that was made with non-noble metal electrocatalysts by using an alkaline anion exchange membrane instead of an acidic proton exchange membrane [15]. This device made of inexpensive materials achieved ca. $74 \%$ electrolysis efficiency and ca. 15\% solar-to-hydrogen efficiency [15]. The high electrolysis efficiency was achieved by operating at low current densities that are compatible with a PV coupled electrolysis device $\left( \pm 10 \mathrm{~mA} / \mathrm{cm}^{2}\right)$, rather than operation at high current densities $\left( \pm 1 \mathrm{~A} / \mathrm{cm}^{2}\right)$ employed in grid-connected electrolysis devices, with typical electrolysis efficiencies of $\pm 65 \%$ for devices based on anion exchange membranes and earth abundant catalysts [17-22]. When comparing the solar-to-hydrogen efficiency with other solar hydrogen generators (Fig. 1) [3,10,15,23-31], only devices with high cost III-V photo absorbers have achieved higher efficiencies. This revealed the potential of using earth-abundant metals and commodity membranes in vapor phase devices.

The water content of ambient air is sufficient to perform water splitting reaction at moderate current densities corresponding to the energy flux from the sun. However, at higher current densities the water is rapidly depleted. 
In the work of Spurgeon and Lewis, a decrease in flow rate of the water vapor inlet stream resulted in a decay in performance which was believed to be caused by mass transfer limitations of water [9]. Modestino et al. also stressed the importance of mass transfer limitations in a vapor-fed device and recommended to increase convection at the gas/electrolyte interface and to improve water uptake by the solid electrolyte [11]. These investigations were both performed on vapor-fed devices with Nafion as solid electrolyte. In this work, a vapor-fed water electrolyzer with poly(vinyl alcohol) anion exchange membrane impregnated with $\mathrm{KOH}$ and flanked with nonnoble metal catalysts was operated over longer time periods in order to probe transient phenomena and the steady state behavior. The relative humidity was varied, and vapor and liquid phase processes were compared.

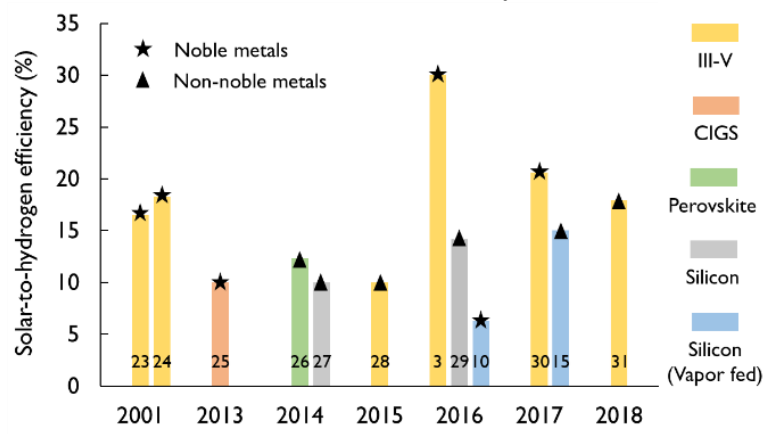

Fig. 1. Highest reported solar-to-hydrogen efficiencies of solar hydrogen generators operated at 1 sun. The type of photoabsorber and catalyst are indicated (yellow: III-V, red: CIGS, green: Perovskite, gray: Silicon, blue: Silicon operated with water vapor, star: noble metal catalysts, triangle: non-noble metal catalysts). Small numbers are added on the bars to refer to the corresponding articles. $[3,10,15,22-31]$.

\section{Experimental}

\subsection{PVA membrane synthesis}

poly(vinyl alcohol) (PVA) membranes were made as described in previous work [15,32]. A PVA polymer solution was prepared by dissolving PVA (99\%, MW 85.000 - 124.000, Sigma-Aldrich) in distilled water at $90{ }^{\circ} \mathrm{C}$ overnight. Afterwards, the temperature was decreased to $40{ }^{\circ} \mathrm{C}$ and glutaraldehyde $(25 \mathrm{wt} \%$ in water, Acros Organics), and several drops of $1 \mathrm{M} \mathrm{NaOH}$ were added into the solution. The total content of PVA and glutaraldehyde in solution amounted $5 \mathrm{wt} . \%$, each. After stirring for $2 \mathrm{~h}$, the viscous mixture was degassed for 15 min in a vacuum oven and dried at $60{ }^{\circ} \mathrm{C}$ for $24 \mathrm{~h}$.

\subsection{Electrode preparation}

Earth abundant NiFe and NiMo electrocatalysts were electrodeposited on pieces of carbon paper substrate (TP060, untreated Toray carbon paper, Quintech). For electric contact, a copper wire was attached on the substrate using silver paint (RS Components) and covered with epoxy resin (Loctite M-121MP Hysol, Henkel). Afterwards, the substrate was cleaned with ethanol and acetone and dried for 60 minutes at $60{ }^{\circ} \mathrm{C}$. The deposition conditions were based on literature [33-35] and were described in previous work [15].

\subsection{Liquid electrolyte electrochemical measurements}

Liquid electrolyte two and three electrode characterization measurements were performed at room temperature in a one-compartment electrochemical cell with volume of approximately $600 \mathrm{~mL}$. The electrolyte was purged with Ar gas and stirred with a magnetic stirring bar. In the cell, each electrodeposited NiFe and NiMo electrode had a fixed position and a single-side geometric surface area of $4 \mathrm{~cm}^{2}$. For three electrode measurements, a graphite counter electrode and a calibrated $\mathrm{Hg} / \mathrm{HgO}$ (1 M KOH) (RE-61AP, Bio-logic) reference electrode were used. Electrochemical measurements were performed using a VersaSTAT 4 potentiostat (Princeton Applied Research). Catalyst activity was investigated with cyclic voltammetry measurements at a scan rate of $1 \mathrm{mV} / \mathrm{s}$. Stability was examined with chronopotentiometry at a current density of $10 \mathrm{~mA} / \mathrm{cm}^{2}$. All reported data were corrected for the uncompensated resistance $\left(\mathrm{R}_{\mathrm{u}}\right)$, which was determined with potentiostatic electrochemical impedance spectroscopy in a frequency region between $100 \mathrm{~Hz}$ and $1 \mathrm{MHz}$, by using the real part of the impedance in the high-frequency region where phase angle was zero.

\subsection{Membrane electrode assembly preparation}

The vapor-fed water electrolyzer was built as described in previous work [15]. In short, before assembling the PVA membrane was immersed in $4 \mathrm{M} \mathrm{KOH}$ for one hour. After removing excess $\mathrm{KOH}$ on the surface, the 
membrane was compressed by hand tightening between electrodeposited NiFe and NiMo catalysts, carbon papers, PTFE gaskets, graphite plates with serpentine gas flow channels and gold-coated copper end plates. The singleside geometric surface area of each electrode amounted to $4 \mathrm{~cm}^{2}$.

\subsection{Vapor-fed water electrolyzer characterization}

Prior to the first experiment, the vapor-fed water electrolyzer was flushed for at least 12 hours with a noncondensing nitrogen gas stream at $92 \% \mathrm{RH}$. The $\mathrm{RH}$ of each electrode compartment was chosen by mixing a constant flow of $100 \mathrm{~mL} / \mathrm{min}$ water-saturated nitrogen gas with a variable flow rate of dry nitrogen gas using mass flow controllers. A RH sensor was placed at the compartment outlets. To compensate for Ohmic losses, the resistance of the device was measured with potentiostatic electrochemical impedance spectroscopy at open circuit potential and in a frequency range from $1 \mathrm{MHz}$ to $100 \mathrm{~Hz}$. The composition of the outlet gas streams of the anode and cathode compartments were further characterized with a mass spectrometer (Quantitative Gas Analyzer, Hiden Analytical, Warrington, UK). The polarization curves were obtained with cyclic voltammetry measurements at a scan rate of $1 \mathrm{mV} / \mathrm{s}$. Stability was examined with chronopotentiometry measurements at a current density of $10 \mathrm{~mA} / \mathrm{cm}^{2}$. All measurements were performed at room temperature and atmospheric pressure.

\section{Results and discussion}

\subsection{Initial activity}

The initial activity of a vapor-fed water electrolyzer was compared to a $1 \mathrm{M} \mathrm{KOH}$ liquid electrolyte by performing cyclic voltammetry measurements. In both systems the same catalysts were used (NiFe and NiMo) with equal single-side geometric surface area $\left(4 \mathrm{~cm}^{2}\right)$. Figure 2 depicts the polarization curves of both systems which were measured at a scan rate of $1 \mathrm{mV} / \mathrm{s}$. After correcting for Ohmic losses, it is observed that both systems have similar activity towards water splitting at low current densities. The slightly lower onset potential for vapor phase electrolysis could be due to a difference in thermodynamic energy requirement [9]. To obtain a current density of $10 \mathrm{~mA} / \mathrm{cm}^{2}$ an IR-corrected potential of 1.56 and $1.55 \mathrm{~V}$ was required in $1 \mathrm{M} \mathrm{KOH}$ electrolyte and in vapor phase, respectively. Therefore, it seems that in this regime the required overpotential is similar for both systems ( $c a .320$ $\mathrm{mV})$. This overpotential is required to compensate for kinetic losses. At higher current densities (> $20 \mathrm{~mA} / \mathrm{cm} 2)$, the polarization curve of the vapor-fed device starts to deviate from the liquid phase measurement and reaches a plateau at ca. $40 \mathrm{~mA} / \mathrm{cm}^{2}$. This kind of plateau was also observed in the work of Spurgeon et al. with Nafion and noble metal catalysts, and was assigned to mass transport limitations of water molecules [9]. The potential difference between vapor and liquid phase measurements is designated as concentration overpotential, indicated with the blue shaded area $\eta_{\mathrm{c}}$ in figure 2 .

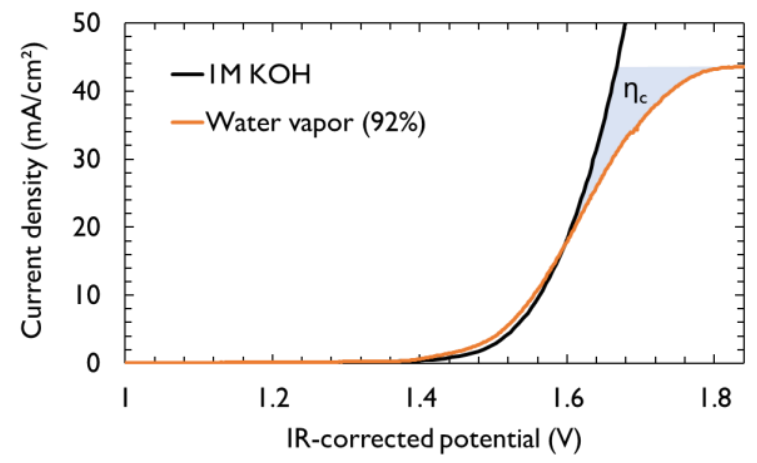

Fig. 2. Polarization curves of a two-electrode measurement operated in $1 \mathrm{M} \mathrm{KOH}$ (black curve) or water vapor at $92 \%$ $\mathrm{RH}$ (orange curve) with NiMo and $\mathrm{NiFe}$ as hydrogen and oxygen evolution reaction catalyst, respectively. The curves were obtained at room temperature and a scan rate of 1 $\mathrm{mV} / \mathrm{s}$. The difference between the two curves is indicated by the blue shaded area and was assigned to concentration overpotential $\left(\eta_{c}\right)$.

\subsection{Relative humidity}

To examine the effect of relative humidity ( $\mathrm{RH}$ ), polarization curves were recorded at $92,87,82$ and $77 \% \mathrm{RH}$ (Fig. 3). It is often stressed that by reducing the RH of the water vapor feed, the membrane dehydrates and loses its conductivity [9]. While this is partially true, Ohmic losses are only a small contributing factor to the total overpotential even at low RH. Correcting for Ohmic losses did not remove the large differences observed in the polarization curves at different humidities (Fig. S1). At lower RH, significant deviations in IR-corrected potential 
are observed and the limiting current density drops to lower values. Both of these effects could be correlated with mass transport limitation of water molecules, which seem to increase significantly at lower RH. After each polarization curve a stability measurement was performed over 1.5 hours to examine the effect of different $\mathrm{RH}$ on device operation (Fig. 4). In this experiment the potential was recorded over time, that was required to sustain a current density of $10 \mathrm{~mA} / \mathrm{cm}^{2}$. At $92 \% \mathrm{RH}$, the potential started off at a potential that was similar $(1.56 \mathrm{~V})$ as observed in the polarization curve in Fig. 2. However, over time it slightly increases to higher values. At lower $\mathrm{RH}$, the potential also increases over time and even starts off at higher potentials than observed in their respective polarization curves. This was due to the fact that the stability measurement was started right after completing the cyclic voltammetry scan. By this time the effect of mass transfer limitations increased, which was also observed in the backward scan of the polarization curves (Fig. S2). Indeed, a polarization curve alone is not sufficient to predict long-term operation of a vapor-fed device. It merely gives a snapshot of the device performance at a certain timeframe. Since the effect of mass transport limitations already resulted in strong deviations in applied potential during a single $\mathrm{CV}$ scan, it is also expected that this effect largely explains the observed increase in potential at the different tested RH in this work.

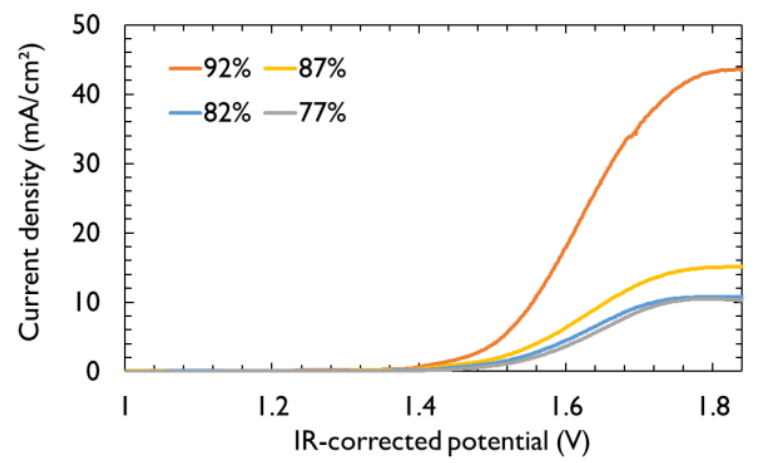

Fig. 3. Polarization curves of the vapor-fed water electrolyzer operated at different relative humidities (orange: $92 \%$, yellow: $87 \%$, blue: $82 \%$ and gray: $77 \%$ ). All curves were obtained at room temperature and a scan rate of $1 \mathrm{mV} / \mathrm{s}$.

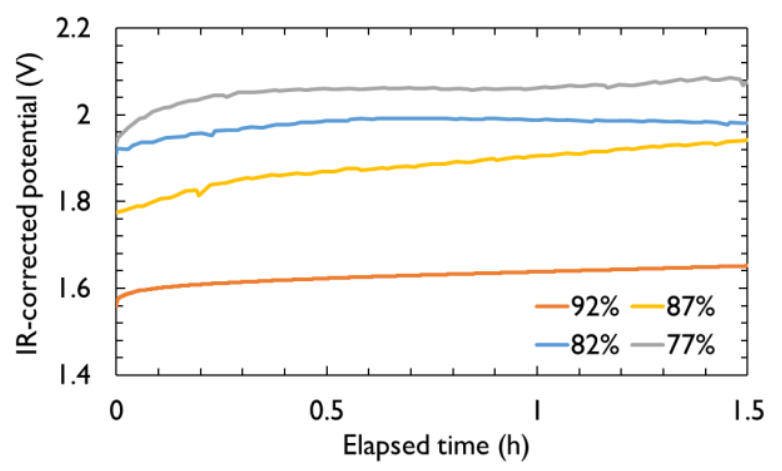

Fig. 4. Required IR-corrected potential over time to sustain a current density of $10 \mathrm{~mA} / \mathrm{cm}^{2}$ in the vapor-fed water electrolyzer, operated at different relative humidities (orange: $92 \%$, yellow: $87 \%$, blue: $82 \%$ and gray: $77 \%$ ). All curves were obtained at room temperature.

\subsection{Stability}

During the chronopotentiometric measurement at $77 \% \mathrm{RH}$, the potential increased to approximately $2.1 \mathrm{~V}$ after $1.5 \mathrm{~h}$ to sustain a current density of $10 \mathrm{~mA} / \mathrm{cm}^{2}$. In order to know whether this increase in potential was permanent or only temporary, the RH was increased back to $92 \%$ and another chronopotentiometric measurement was performed (Fig. 5). In this experiment the applied potential was recorded over a much longer time span of $90 \mathrm{~h}$. During this measurement, the potential started off at a potential around $1.6 \mathrm{~V}$ but then quickly increased to ca. 1.7 $\mathrm{V}$, which is still much lower than the $2.1 \mathrm{~V}$ required at $77 \% \mathrm{RH}$. This illustrates that the increased potential at $77 \%$ RH is merely a temporary result of mass transport limitations, making the system reversible. Interestingly, it was observed that the applied potential initially continued to rise but after $9 \mathrm{~h}$ it seemed to have reached a steady state. This increase in potential was not directly correlated with a rise in Ohmic losses, which only increased by $12 \mathrm{mV}$. Therefore, under these conditions, this device appears to be working in a non-equilibrium for the first 9 
hours, in which it consumes water which is not completely originating from the water vapor stream. After 9 hours, this transient effect is over and a steady potential is reached. The variations in potential at steady state are presumed to be caused by slight changes in environmental conditions such as temperature, influencing the mass transfer of water molecules and locally changing the RH. By performing water sorption measurements, it was observed that the membrane itself absorbs quite an amount of water at high RH (Fig. S3). Therefore, it seems that water that is absorbed in the membrane might serve as a water buffer. We note that this device was run continuously for more than $90 \mathrm{~h}$ at a current density corresponding with full illumination. These are conditions that far exceed the typical operation of a solar hydrogen generator but they were used in this work to gain more insight in the steady state behavior of the device. In real-life applications, the device will be subjected to changing weather conditions including illumination intensity, humidity levels and wind speeds, which could allow the system to operate at a lower potential during daytime. A standard operating procedure for short- and long-term characterization is needed for these type of solar hydrogen generators to investigate the effect of real-life conditions.

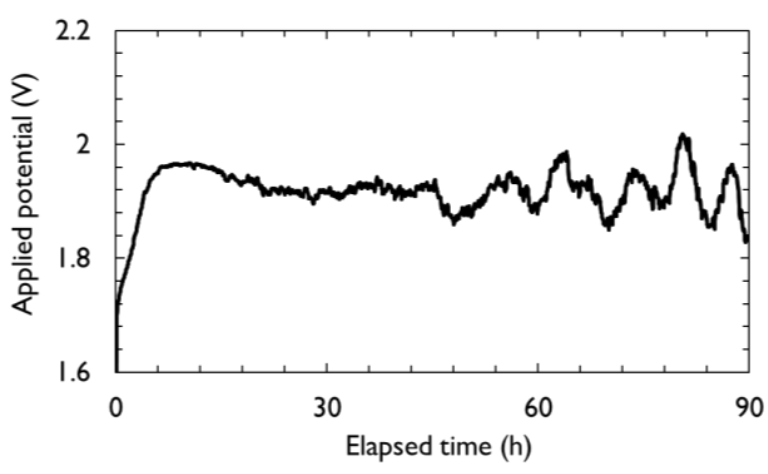

Fig. 5. Potential required to sustain a current density of 10 $\mathrm{mA} / \mathrm{cm}^{2}$ in the vapor-fed water electrolyzer that was operated at $92 \%$ relative humidity and room temperature.

\section{4. $\mathrm{D}_{2} \mathrm{O}$ isotope measurement}

In order to obtain more insight into the water buffering effect of the membrane, an experiment with $\mathrm{D}_{2} \mathrm{O}$ was performed. In this experiment, $\mathrm{D}_{2} \mathrm{O}$ saturators were used instead of $\mathrm{H}_{2} \mathrm{O}$ saturators. Before using the $\mathrm{D}_{2} \mathrm{O}$ saturators, the system was first flushed with $\mathrm{H}_{2} \mathrm{O}$ vapor at $92 \% \mathrm{RH}$ for $24 \mathrm{~h}$, presumably saturating the membrane with $\mathrm{H}_{2} \mathrm{O}$. When the gas inlet streams were switched to the $\mathrm{D}_{2} \mathrm{O}$ saturators, a chronopotentiometric measurement was immediately started at a current density of $10 \mathrm{~mA} / \mathrm{cm}^{2}$. Splitting of $\mathrm{D}_{2} \mathrm{O}$ should thus lead to the formation of $\mathrm{D}_{2}$ and $\mathrm{O}_{2}$. However, due to the presaturation with $\mathrm{H}_{2} \mathrm{O}$ vapor, initially $\mathrm{H}_{2} \mathrm{O}$ is still present in the system. This leads to the formation of $\mathrm{H}_{2}$ initially (Fig. 6). Over time $\mathrm{H}_{2}$ production was reduced and $\mathrm{HD}$ and $\mathrm{D}_{2}$ production increased. After approximately 4 hours, HD production reaches its maximum and $\mathrm{D}_{2}$ is being dominantly produced. It seems that initially the absorbed water in the system is being consumed to produce $\mathrm{H}_{2}$. Gradually, also water is consumed from the $\mathrm{D}_{2} \mathrm{O}$ saturated vapor to produce either $\mathrm{HD}$ or $\mathrm{D}_{2}$. Finally, when most of the absorbed water is consumed, dominantly $\mathrm{D}_{2}$ is being produced. This also explains the observed trend in the stability measurement, in which initially a lot of absorbed water is present in the membrane and thus only low applied potentials are required to achieve $10 \mathrm{~mA} / \mathrm{cm}^{2}$. After some time, this water buffer is being depleted and water is required from the vapor phase. Due to mass transfer limitations of water, additional overpotential has to be applied to sustain the current density of $10 \mathrm{~mA} / \mathrm{cm}^{2}$. 
Overall, the system seems to transfer from a state where it consumes absorbed water towards a state where it consumes water from vapor phase in which mass transfer limitations are present. This was also observed in the polarization curves scanned at $1 \mathrm{mV} / \mathrm{s}$ before and after the stability measurement (Fig. S4). After the stability

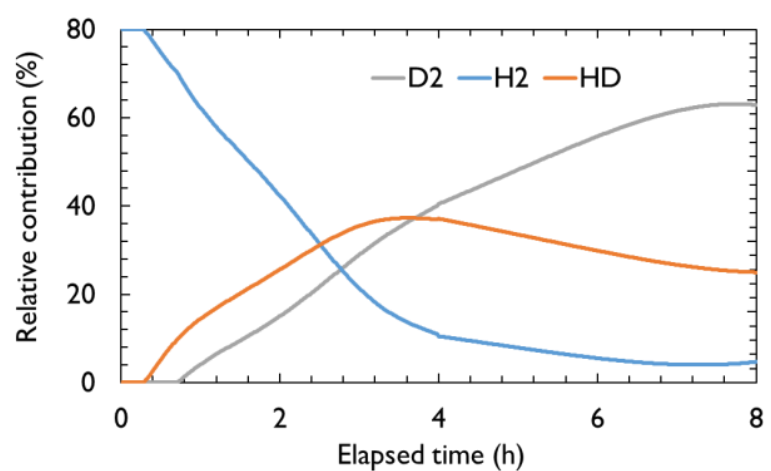

Fig. 6. Product composition at the cathode comparment of the vapor-fed water electrolyzer that was operated with $\mathrm{D}_{2} \mathrm{O}$ saturators.

measurement, a dramatic shift in limiting current density was observed which also confirms the presence of increased diffusion limitations over time.

\subsection{Stability of electrodes}

During the performed stability measurements, an increase in potential was observed. This increase was largely assigned to mass transfer limitations since the increase in Ohmic losses was insignificant. Another effect that hasn't been discussed yet are kinetic losses. So far, it was assumed that the kinetic losses remained unchanged over time and thus no deterioration of the electrodeposited NiFe and NiMo catalysts. It is known, however, that compositional changes in NiFe [36] and NiMo [37] catalysts can occur in alkaline media that can alter their activity. In order to examine the stability of the catalysts synthesized in this work, the IR-corrected potential that was required to sustain a current density of $10 \mathrm{~mA} / \mathrm{cm}^{2}$ in a $1 \mathrm{M} \mathrm{KOH}$ liquid electrolyte was recorded (Fig. 7). Over a $15 \mathrm{~h}$ timespan, the required IR-corrected potential barely changed. It decreased initially to $1.58 \mathrm{~V}$ and then increased to $1.59 \mathrm{~V}$ over the entire duration of the experiment. A similar trend was observed when characterizing the bare catalysts in a three electrode setup (Fig. S5), in which NiMo became more active towards hydrogen evolution initially but $\mathrm{NiFe}$ slightly decreased in activity over time. Based on these data, we conclude that changes in kinetic overpotential can explain only a small part of the observed potential changes in our stability experiments.

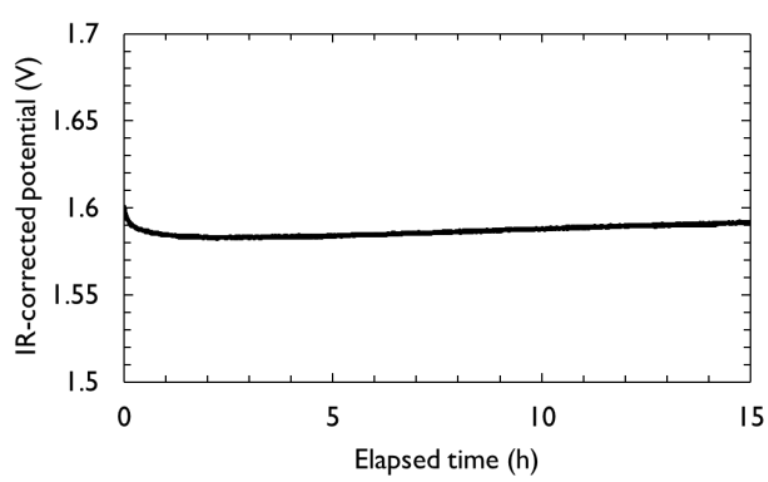

Fig. 7. IR-corrected potential required to sustain a current density of $10 \mathrm{~mA} / \mathrm{cm}^{2}$ in $1 \mathrm{M} \mathrm{KOH}$ with a NiMo and $\mathrm{NiFe}$ hydrogen and oxygen evolution reaction catalyst.

\section{6. $\mathrm{pH}$ polarization of $\mathrm{KOH}$}

Another possible effect that was not yet taken into account is the formation of an ion concentration gradient. Since the PVA anion exchange membrane is impregnated with $4 \mathrm{M} \mathrm{KOH}$ electrolyte that has mobile cation and anion charges, the formation of a $\mathrm{pH}$ polarization effect within the membrane cannot be excluded. Such a $\mathrm{pH}$ polarization would result in an increase in potential. It is caused by non-unity transference numbers of protons or hydroxide ions and is common in liquid phase electrolysis, especially at mild $\mathrm{pH}$ [38,39]. For a pure electrolyte, such as $\mathrm{KOH}$, the transference number of an ion is only dependent on its contribution towards the total mobility [40].

$$
t_{i}=\frac{u_{i}}{u_{+}+u_{-}}
$$


This leads to $\mathrm{OH}^{-}$and $\mathrm{K}^{+}$transference numbers of 0.73 and 0.27 , respectively [40]. Because of the non-unity transfer number of $\mathrm{OH}^{-}$, pH polarization effects are expected to occur (Fig. S6). In this case, the concentration of hydroxide ions will become higher at the cathode side compared to the anode side. According to Nernst law, this could increase the total potential that has to be applied to sustain the water splitting reaction.

$$
\begin{gathered}
E_{\mathrm{H} 2 / \mathrm{H} 2 \mathrm{O}}=E_{\mathrm{H} 2 / \mathrm{H} 2 \mathrm{O}}^{0}-0.0592 \mathrm{pH}_{\mathrm{H} 2 / \mathrm{H} 2 \mathrm{O}} \\
E_{\mathrm{O} 2 / \mathrm{OH}-}=E_{\mathrm{O} / \mathrm{OH}-}^{0}-0.0592 p \mathrm{H}_{\mathrm{O} 2 / \mathrm{OH}-} \\
E_{\text {tot }}=1.229+0.0592\left(p \mathrm{H}_{\mathrm{H} 2 / \mathrm{H} 2 \mathrm{O}}-p \mathrm{H}_{\mathrm{O} 2 / \mathrm{OH}-}\right)
\end{gathered}
$$

In order to examine whether this effect is occurring, two NiFe electrodes with equal single-side geometric surface area were immersed in $0.1 \mathrm{M} \mathrm{KOH}$. In this experiment, the IR-corrected potential was measured that had to be applied to sustain a current density of $10 \mathrm{~mA} / \mathrm{cm}^{2}$ for $10 \mathrm{~h}$ and $-10 \mathrm{~mA} / \mathrm{cm}^{2}$ for another $10 \mathrm{~h} \mathrm{(Fig.} \mathrm{8).}$

When changing the polarity of the current, the concentration of hydroxide ions should now be lower at the cathode side compared to the anode side and thus a decrease in potential should be observed. This was not the case. Any potential difference caused by $\mathrm{pH}$ polarization was too small to be observed in our setup. This experiment confirms that $\mathrm{pH}$ polarization effects do not play a significant role even at modest $\mathrm{KOH}$ concentrations of $0.1 \mathrm{M}$. We therefore expect that polarization will also not occur in the PVA membrane impregnated with $4 \mathrm{M} \mathrm{KOH}$.

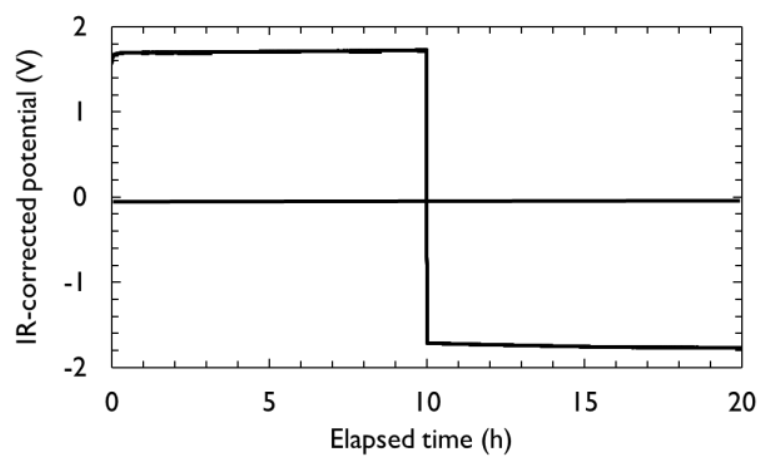

Fig. 8. Required applied IR-corrected potential over time to sustain a current density of $10 \mathrm{~mA} / \mathrm{cm}^{2}$ in $0.1 \mathrm{M} \mathrm{KOH}$ with two NiFe electrodes for both hydrogen and oxygen evolution reactions. After $10 \mathrm{~h}$ the current was changed in polarity to $-10 \mathrm{~mA} / \mathrm{cm}^{2}$.

\section{Summary and conclusions}

In this work, the stability of a vapor-fed water electrolyzer with PVA anion exchange membrane impregnated with $4 \mathrm{M} \mathrm{KOH}$ solution and electrodeposited NiMo and NiFe catalysts was investigated. At low current densities the initial activity in vapor phase and liquid phase were similar. At higher current densities, however, the performance started to deviate due to mass transfer limitations of water molecules to the electrodes. These limitations give rise to increased overpotential and a maximum current density of ca. $40 \mathrm{~mA} / \mathrm{cm}^{2}$. When lowering relative humidity, these mass transfer limitations became more pronounced. The obtained polarization curves were found to merely give a snapshot of device performance within a brief timespan, and transient effects were observed over the course of hours before steady state performance was reached. The operating potential increased to higher values at steady state. This was attributed to mass transfer limitations of water that increased over time, since the changes in kinetic and Ohmic losses were not significant. The increase in potential was also not correlated with $\mathrm{pH}$ polarization within the $\mathrm{KOH}$ electrolyte. By feeding $\mathrm{D}_{2} \mathrm{O}$ vapor to a $\mathrm{H}_{2} \mathrm{O}$-saturated device, it was found that absorbed water seems to serve as a water buffer that keeps the required potential low during the first hours of operation. Over time, this buffer is consumed and water molecules need to be delivered from the vapor phase. Once this mass transfer balances the consumption of water molecules in water splitting reactions, a steady state potential is reached. We have shown stable operation at steady state at a potential of ca. $1.9 \mathrm{~V}$ during more than $90 \mathrm{~h}$. Future research should optimize the mass transfer of water molecules to shift the operating point towards a lower steady state potential and to operate at lower relative humidity. In addition, more research is needed to understand the impact of variable current profiles of a real-life solar hydrogen generator on long-term stability and water management. 


\section{Acknowledgements}

This work was performed in the framework of the SBO project CATCO2RE (no. S004118N), with the financial support of the Research Foundation - Flanders (FWO). J.R. is a postdoctoral fellow of the Research Foundation - Flanders (FWO). J.A.M. acknowledges the Flemish Government for long-term structural funding (Methusalem).

\section{Appendix A. Supplementary data}

Supplementary data associated with this article can be found, in the online version

\section{References}

[1] R. Van De Krol, M. Grätzel, Photoelectrochemical Hydrogen Production, Springer, 2012.

[2] J. Rongé, T. Bosserez, L. Huguenin, M. Dumortier, S. Haussener, J.A. Martens, Solar Hydrogen Reaching Maturity, Oil Gas Sci. Technol. - Rev. d'IFP Energies Nouv. 70 (2015) 863-876.

[3] J. Jia, L.C. Seitz, J.D. Benck, Y. Huo, Y. Chen, J.W.D. Ng, T. Bilir, J.S. Harris, T.F. Jaramillo, Solar water splitting by photovoltaic-electrolysis with a solar-to-hydrogen efficiency over 30\%, Nat. Commun. 7 (2016) 13237.

[4] M. Reuß, T. Grube, M. Robinius, P. Preuster, P. Wasserscheid, D. Stolten, Seasonal storage and alternative carriers: A flexible hydrogen supply chain model, Appl. Energy. 200 (2017) 290-302.

[5] J. Töpler, J. Lehmann, Hydrogen and Fuel Cell: Technologies and Market Perspectives, Springer, 2014.

[6] J.W. Ager, M.R. Shaner, K.A. Walczak, I.D. Sharp, S. Ardo, Experimental demonstrations of spontaneous, solar-driven photoelectrochemical water splitting, Energy Environ. Sci. 8 (2015) 2811-2824.

[7] F. Dionigi, P.C.K. Vesborg, T. Pedersen, O. Hansen, S. Dahl, A. Xiong, K. Maeda, K. Domen, I. Chorkendorff, Gas phase photocatalytic water splitting with Rh2-yCryO3/GaN:ZnO in $\mu$-reactors, Energy Environ. Sci. 4 (2011) 2937-2942.

[8] J. Rongé, S. Deng, S.P. Sree, T. Bosserez, S.W. Verbruggen, N. Kumar Singh, J. Dendooven, M.B.J. Roeffaers, F. Taulelle, M. De Volder, C. Detavernier, J.A. Martens, Air-based photoelectrochemical cell capturing water molecules from ambient air for hydrogen production, RSC Adv. 4 (2014) 29286-29290.

[9] J.M. Spurgeon, N.S. Lewis, Proton exchange membrane electrolysis sustained by water vapor, Energy Environ. Sci. 4 (2011) 2993-2998.

[10] S. Kumari, R.T. White, B. Kumar, J.M. Spurgeon, Solar Hydrogen Production from Seawater Vapor Electrolysis, Energy Environ. Sci. 9 (2016) 1725-1733.

[11] M.A. Modestino, M. Dumortier, S.M. Hosseini Hashemi, S. Haussener, C. Moser, D. Psaltis, Vapor-fed microfluidic hydrogen generator, Lab Chip. 15 (2015) 2287-2296.

[12] T. Daeneke, N. Dahr, P. Atkin, R.M. Clark, C.J. Harrison, R. Brkljaca, N. Pillai, B.Y. Zhang, A. Zavabeti, S.J. Ippolito, K.J. Berean, J. Zhen Ou, M.S. Strano, K. Kalantar-zadeh, Surface Water Dependent Properties of Sulfur- Rich Molybdenum Sulfides: Electrolyteless Gas Phase Water Splitting, ACS Nano. 11 (2017) 6782-6794. [13] T. Yao, X. An, H. Han, J.Q. Chen, C. Li, Photoelectrocatalytic Materials for Solar Water Splitting, Adv. Energy Mater. (2018).

[14] S. Sawada, T. Yamaki, T. Maeno, M. Asano, A. Suzuki, T. Terai, Y. Maekawa, Solid polymer electrolyte water electrolysis systems for hydrogen production based on our newly developed membranes, Part I: Analysis of voltage-current characteristics, Prog. Nucl. Energy. 50 (2008) 443-448.

[15] G. Heremans, C. Trompoukis, N. Daems, T. Bosserez, I.F.J. Vankelecom, J.A. Martens, J. Rongé, Vaporfed solar hydrogen production exceeding $15 \%$ efficiency using earth abundant catalysts and anion exchange membrane, Sustain. Energy Fuels. 1 (2017) 2061-2065.

[16] T. Stoll, G. Zafeiropoulos, I. Dogan, H. Genuit, R. Lavrijsen, B. Koopmans, M.N. Tsampas, Visiblelight-promoted gas-phase water splitting using porous WO3/BiVO4photoanodes, Electrochem. Commun. 82 (2017) 47-51.

[17] C.C. Pavel, F. Cecconi, C. Emiliani, S. Santiccioli, A. Scaffidi, S. Catanorchi, M. Comotti, Highly efficient platinum group metal free based membrane-electrode assembly for anion exchange membrane water electrolysis, Angew. Chemie - Int. Ed. 53 (2014) 1378-1381.

[18] J.J. Kaczur, H. Yang, Z. Liu, S.D. Sajjad, R.I. Masel, Carbon Dioxide and Water Electrolysis Using New Alkaline Stable Anion Membranes, Front. Chem. 6 (2018) Article 263.

[19] L. Xiao, S. Zhang, J. Pan, C. Yang, M. He, L. Zhuang, J. Lu, First implementation of alkaline polymer electrolyte water electrolysis working only with pure water, Energy Environ. Sci. 5 (2012) 7869-7871.

[20] T. Pandiarajan, J.L. Berchmans, S. Ravichandran, Fabrication of spinel ferrite based alkaline anion exchange membrane water electrolysers for hydrogen production, RSC Adv. 5 (2015) 34100-34108.

[21] I. Vincent, A. Kruger, D. Bessarabov, Development of efficient membrane electrode assembly for low cost hydrogen production by anion exchange membrane electrolysis, Int. J. Hydrogen Energy. 42 (2017) 1075210761. 
[22] L. An, T.S. Zhao, Z.H. Chai, P. Tan, L. Zeng, Mathematical modeling of an anion-exchange membrane water electrolyzer for hydrogen production, Int. J. Hydrogen Energy. 39 (2014) 19869-19876.

[23] O. Khaselev, A. Bansal, J.A. Turner, High-efficiency integrated multijunction photovoltaic/electrolysis systems for hydrogen production, Int. J. Hydrogen Energy. 26 (2001) 127-132.

[24] S. Licht, B. Wang, S. Mukerji, T. Soga, M. Umeno, H. Tributsch, Over $18 \%$ solar energy conversion to generation of hydrogen fuel; theory and experiment for efficient solar water splitting, Int. J. Hydrogen Energy. 26 (2001) 653-659.

[25] T.J. Jacobsson, V. Fjällström, M. Sahlberg, M. Edoff, T. Edvinsson, A monolithic device for solar water splitting based on series interconnected thin film absorbers reaching over 10\% solar-to-hydrogen efficiency, Energy Environ. Sci. 6 (2013) 3676-3683.

[26] J. Luo, J.-H. Im, M.T. Mayer, M. Schreier, M.K. Nazeeruddin, N.-G. Park, S.D. Tilley, H.J. Fan, M. Gratzel, Water photolysis at $12.3 \%$ efficiency via perovskite photovoltaics and Earth-abundant catalysts, Science 345 (2014) 1593-1596.

[27] C.R. Cox, J.Z. Lee, D.G. Nocera, T. Buonassisi, Ten-percent solar-to-fuel conversion with nonprecious materials, Proc. Natl. Acad. Sci. 111 (2014) 14057-14061.

[28] E. Verlage, S. Hu, R. Liu, R.J.R. Jones, K. Sun, C. Xiang, N.S. Lewis, H.A. Atwater, A monolithically integrated, intrinsically safe, $10 \%$ efficient, solar-driven water-splitting system based on active, stable earthabundant electrocatalysts in conjunction with tandem III-V light absorbers protected by amorphous TiO2 films, Energy Environ. Sci. 8 (2015) 3166-3172.

[29] J.-W. Schüttauf, M.A. Modestino, E. Chinello, D. Lambelet, A. Delfino, D. Dominé, A. Faes, M. Despeisse, J. Bailat, D. Psaltis, C. Moser, C. Ballif, Solar-to-Hydrogen Production at 14.2\% Efficiency with Silicon Photovoltaics and Earth-Abundant Electrocatalysts, J. Electrochem. Soc. 163 (2016) F1177-F1181.

[30] W.J. Chang, K.H. Lee, H. Ha, K. Jin, G. Kim, S.T. Hwang, H.M. Lee, S.W. Ahn, W. Yoon, H. Seo, J.S. Hong, Y.K. Go, J.I. Ha, K.T. Nam, Design Principle and Loss Engineering for Photovoltaic-Electrolysis Cell System, ACS Omega. 2 (2017) 1009-1018.

[31] S.H. Hsu, J. Miao, L. Zhang, J. Gao, H. Wang, H. Tao, S.F. Hung, A. Vasileff, S.Z. Qiao, B. Liu, An Earth-Abundant Catalyst-Based Seawater Photoelectrolysis System with 17.9\% Solar-to-Hydrogen Efficiency, Adv. Mater. 30 (2018) 1707261.

[32] L. Zeng, T.S. Zhao, Integrated inorganic membrane electrode assembly with layered double hydroxides as ionic conductors for anion exchange membrane water electrolysis, Nano Energy. 11 (2015) 110-118.

[33] R. Solmaz, G. Kardas, Electrochemical deposition and characterization of NiFe coatings as electrocatalytic materials for alkaline water electrolysis, Electrochim. Acta. 54 (2009) 3726-3734.

[34] E. Navarro-Flores, Z. Chong, S. Omanovic, Characterization of Ni, NiMo, NiW and NiFe electroactive coatings as electrocatalysts for hydrogen evolution in an acidic medium, J. Mol. Catal. A Chem. 226 (2005) 179197.

[35] C.C.L. McCrory, S. Jung, I.M. Ferrer, S.M. Chatman, J.C. Peters, T.F. Jaramillo, Benchmarking Hydrogen Evolving Reaction and Oxygen Evolving Reaction Electrocatalysts for Solar Water Splitting Devices, J. Am. Chem. Soc. 137 (2015) 4347-4357.

[36] F.D. Speck, K.E. Dettelbach, R.S. Sherbo, D.A. Salvatore, A. Huang, C.P. Berlinguette, On the Electrolytic Stability of Iron-Nickel Oxides, Chem. 2 (2017) 590-597.

[37] M. Schalenbach, F.D. Speck, M. Ledendecker, O. Kasian, D. Goehl, A.M. Mingers, B. Breitbach, H. Springer, S. Cherevko, K.J.J. Mayrhofer, Nickel-molybdenum alloy catalysts for the hydrogen evolution reaction: Activity and stability revised, Electrochim. Acta. 259 (2017) 1154-1161.

[38] M.R. Singh, K. Papadantonakis, C. Xiang, N.S. Lewis, An electrochemical engineering assessment of the operational conditions and constraints for solar-driven water-splitting systems at near-neutral $\mathrm{pH}$, Energy Environ. Sci. 8 (2015) 2760-2767.

[39] E.A. Hernandez-Pagan, N.M. Vargas-Barbosa, T. Wang, Y. Zhao, E.S. Smotkin, T.E. Mallouk, Resistance and polarization losses in aqueous buffer-membrane electrolytes for water-splitting photoelectrochemical cells, Energy Environ. Sci. 5 (2012) 7582-7589.

[40] A.J. Bard, L.R. Faulkner, Electrochemical Methods: Fundamentals and Applications, John Wiley \& Sons, Inc., 2001. 